\title{
ASSESMENT OF CORONARY ARTERY BYPASS GRAFTS BY MULTIDETECTOR CT
}

\author{
By
El-Sayed Ahmed Saeed Ahmed*, Ahmed Abd El-Fattah Abu-Rashed*, Mahmoud Ibrahim El-Shamy* and Ismail Nasr El-Sokkary**

Department of Radiology* and Cardiothorathic Surgery**, Faculty of Medicine, Al-Azhar University

Corresponding Author: El-Sayed Ahmed Saeed Ahmed,

Phone: +201142176200, E-mail: doc.elsayed@ gmail.com

\begin{abstract}
Background: Multidetector computed tomography (MDCT) had made a revolution in coronary artery bypass grafts $(\mathrm{CABG})$ evaluation due to high temporal and spatial resolution beside it is beingnon invasive and highly effective in assessment of extra coronary manifestations.

Objective: To evaluate the feasibility of high-quality multi-detector computed tomography ((MDCT) in assessment of CABG patients in comparison with conventional coronary angiography.

Patients and methods: Fifty patients were enrolled for ECG gated CT of coronary arteries bypass grafts between MAY 2020 and September 2020. Patients subjected to conventional coronary angiography within 10days after MDCT exam. at Al-Hussein University Hospital. Administration of beta blocker and nitroglycerin was done prior to CT exam. Breath hold training was mandatory.

Results: Forty six grafts were arterial and 74 were venous. Thirty six of the arterial grafts $(78.2 \%)$ were patent, $6(13 \%)$ were significantly narrowed and $4(8.8 \%)$ were completely occluded. Regarding venous grafts, $52(70.2 \%)$ of them were patent, $14(19 \%)$ were significantly narrowed, $8(10.8 \%)$ were completely occluded. CT angiography compared to the conventional angiography as a gold standard technique gave us a sensitivity of $100 \%$, a specificity of about $98 \%$ and an accuracy of about $93.6 \%$ in the assessment of any type of coronary artery grafts.
\end{abstract}

Conclusion: Multi Detector CT is considered the imaging modality of choice at the current days to evaluate the patency and stenosis of coronary artery bypass grafts than the conventional coronary angiography due to its multiple drawbacks.

Keywords: MDCT, CABGs, Coronary Artery Disease.

\section{INTRODUCTION}

Coronary artery bypass graft (CABG) surgery has been a mainstream surgical procedure for coronary artery disease for the past three decades (Levisman et al., 2010).

CABG surgery is associated with an improvement of survival and quality of life in patients with multivessel coronary disease, However CABGs, similarly to the native coronary vessels, may in time, develop stenosis or occlusion (Ascarelli et al., 2010).

Conduits used for CABG surgery are either arterial or venous grafts. Venous grafts have demonstrated tendency to develop partial or complete occlusions with time, whereas arterial grafts have shown relative resistance to plaque 
formation and obstruction (Gaudino et al., 2017).

So far, conventional angiography is considered the standard of reference for evaluation of the coronary artery bypass grafts regarding patency and stenosis. However, such procedure is limited by its invasive nature, patient discomfort and risk of complications. A less invasive imaging modality is desirable for evaluation of the coronary artery bypass grafts (Graaf et al., 2011).

Multi detector $\mathrm{CT}$ is considered a noninvasive and convenient tool in the study of CABGs in patients with recurrence of chest pain with its significant increase in spatial and temporal resolution allow cardiac $\mathrm{CT}$ to have an increasing role in the clinical practice (Ascarelli et al., 2010).

That is why 64-Slice coronary computed tomographic angiography (CCTA) has been established as an accurate alternative to invasive coronary artery angiography for postoperative evaluation of bypass grafts (Levisman et al., 2011).

The advent of multi detector computed tomography (CT), particularly with scanners having 64 or more detectors, has continued to improve temporal resolution and allows the acquisition of isotropic voxels. With these scanners, the heart and coronary arteries are routinely imaged as a motion-free volume of data. A variety of post processing techniques, including multi planar reformation (MPR), maximum intensity projection (MIP), volume rendering (VR), curved reformation, and cine imaging, allow noninvasive assessment of every aspect of the cardiovascular system (Aghayev et al., 2016).

The present work aimed to evaluate the feasibility of high-quality multidetector computed tomography ((MDCT) in assessment of CABG patients in comparison with conventional coronary angiography.

\section{PATIENTS AND METHODS}

A total of fifty patients were included in the study from MAY 2020 to SEPTEMBER 2020 at AL-Hussein university hospital. They were 48 males (96\%) and 2 females (4\%), their age ranged from 41 to 71 years. The patients were able to read and give consents. Patients were referred from the cardiology outpatient clinics \& Cardio-thoracic Hospital inpatient, AL-Hussein University hospital.

The inclusion criteria included patients with post-operative need to assess the patency of their grafts, rule out any postoperative complications, Patients with renal insufficiency or presented with arrhythmia were excluded.

MDCT protocol: All patients were instructed to fast 6 hours prior to the examination. Before the examination; the heart rate was evaluated. Patients with pre-examination heart rate above $65 \mathrm{bpm}$ were given a cardio-selective betablocker to obtain a stable low heart rate. If heart rate was still above $65 \mathrm{bpm}$, the examination was postponed to another setting. All steps of the study were explained in detail to each patient. CT examinations were performed with a 128slice Toshiba Aquilion 128 CT scanner (Toshiba, Japan). 
A non-contrast poster anterior projection image of the chest was acquired to determine the position of the heart and aortic arch and to define the scan volume for further imaging. The scanning direction was craniocaudal during a single inspiratory breath-hold, and the ECG signal was recorded simultaneously. For acquisition of the volume data set, an automated dual-head injector was used for IV administration of a bolus of $80 \mathrm{ml}$ of contrast agent (Scanlux 370) followed by $60 \mathrm{ml}$ saline solution, both at a rate of 5 $\mathrm{ml} / \mathrm{s}$. Bolus tracking, All examinations were performed without complications.

Invasive coronary angiography (ICA): Conventional invasive angiography, which was the standard of reference for the comparison of MSCT results, was performed according to standard techniques. The interval between the CT examination and ICA was 10 days at the most. The angiograms were evaluated by two cardiologists, blinded to the MSCT results, using the 15-segment coronary tree ACC/AHA model.

Statistical analysis: Data were analyzed using Statistical Program for Social Science (SPSS) version 24. Qualitative data were expressed as frequency and percentage.

Mean (average): The central value of a discrete set of numbers, specifically the sum of values divided by the number of values. P-value $<0.05$ was considered significant.

\section{RESULTS}

Male patients were the most prone to coronary artery bypass grafts surgery especially the smoker ones (Table 1).

Table (1): Demographic Data of patients

\begin{tabular}{|c|c|}
\hline Parameters & Number \\
\hline Age & 41-71 years old with the mean: 56 y \\
\hline Sex & Fale: $48(96 \%)$ \\
& Female: $2(4 \%)$ \\
\hline Diabetes Mellitus & $40(80 \%)$ \\
\hline Hypertension & $42(84 \%)$ \\
\hline Smoking & $45(90 \%)$ \\
\hline Dyslipidemia & $35(70 \%)$ \\
\hline
\end{tabular}

There was no statistically difference between the MDCT and invasive coronary angiography (ICA) (p-value > 0.05) in assessment of arterial and venous grafts as regard patency, significant stenosis and occlusion (Table 2). 
Table (2): Comparison between MDCT and ICA in all studied population according to graft patency, significant stenosis and occlusion

\begin{tabular}{|c|c|c|c|c|c|c|}
\hline \multicolumn{2}{|c|}{ Graft Pathology } & \multicolumn{2}{|c|}{ MDCT } & \multicolumn{2}{|c|}{ ICA } & \multirow{2}{*}{ p-value } \\
\hline \multirow{2}{*}{$\begin{array}{c}\text { Arterial } \\
(\mathbf{n}=\mathbf{4 6})\end{array}$} & Patent & 33 & $71.7 \%$ & 36 & $78.2 \%$ & \multirow{3}{*}{0.694} \\
\cline { 2 - 6 } & Sig. stenosis & 9 & $19.5 \%$ & 6 & $13 \%$ & \\
\cline { 2 - 7 } & Occluded & 4 & $8.8 \%$ & 4 & $8.8 \%$ & \\
\hline \multirow{2}{*}{$\begin{array}{c}\text { Venous } \\
(\mathbf{n}=\mathbf{7 4})\end{array}$} & Patent & 51 & $68.9 \%$ & 52 & $70.2 \%$ & \multirow{2}{*}{0.978} \\
\cline { 2 - 6 } & Sig. stenosis & 15 & $20.3 \%$ & 14 & $19 \%$ & \\
\cline { 2 - 6 } & Occluded & 8 & $10.8 \%$ & 8 & $10.8 \%$ & \\
\hline
\end{tabular}

The insitu arterial grafts were used more common than the free arterial grafts, as the later has higher rate of complications. The left internal mammary artery (LIMA) was the most widely used insitu arterial graft (Table 3).

Table (3): represents types and numbers of the arterial grafts included in the study and their degree of patency

\begin{tabular}{|c|c|}
\hline \multicolumn{2}{|c|}{ Arterial grafts (46) } \\
\hline Free: 7 (15.3 \%) & In situ: 39 (84.7 \%) \\
\hline Degree of patency & Types: \\
\hline$=4(57.1 \%)$ patent & LIMA: $33(84.6 \%)$ \\
\hline$=2(28.6 \%)$ narrow & Anastomosis: \\
\hline$=1(14.3 \%)$ occluded & $=34(87.2 \%)$ to LAD \\
\hline & $=2(5.1 \%)$ to OM \\
\hline & $=2(5.1 \%)$ to RCA \\
\hline & $=1(2.6 \%)$ to D1 \\
\hline & Degree of patency \\
\hline & $=32(82 \%)$ patent \\
\hline \multicolumn{2}{|c|}{$=4(10.3 \%)$ narrow } \\
\hline \multicolumn{2}{|c|}{$=3(7.7 \%)$ occluded } \\
\hline \multicolumn{2}{|c|}{ Degree of patency of all arterial grafts: } \\
$=36(78.3 \%)$ patent \\
$=6(13 \%)$ narrow \\
$=4(8.7 \%)$ occluded
\end{tabular}

Venous grafts were still the most widely used type of grafts due to their abundance. Yet, there was a high rate of complications with venous grafts due to their high rate of occlusion and narrowing (Table 4).

Table (4): Types and numbers of the venous grafts included in the study considering their degree of patency

\begin{tabular}{|c|c|}
\hline \multicolumn{2}{|c|}{ Venous grafts (74) } \\
\hline Anastomosis: & Degree of patency \\
$=20(27 \%)$ to LAD & $=$ Patent $52(70.3 \%)$ \\
$=35(47.3 \%)$ to OM & $=$ Narrow $14(18.9 \%)$ \\
$=10(13.5 \%)$ to RCA & $=$ Occluded $8(10.8 \%)$ \\
$=5(6.8 \%)$ to D1 & \\
$=4(5.4 \%)$ to PDA & \\
\hline
\end{tabular}


In comparison to invasive coronary angiography as gold standard for our study MDCT has high sensitivity, specificity and accuracy (Table 5).

Table (5): shows sensitivity, specificity \& diagnostic accuracy of the MDCT coronary angiography in evaluation of coronary artery bypass grafts patency.

\begin{tabular}{|c|c|}
\hline Sensitivity & $100 \%$ \\
\hline Specificity & $98 \%$ \\
\hline Accuracy & $93.6 \%$ \\
\hline
\end{tabular}

\section{DISCUSSION}

Although the reference standard to evaluate the patency of such grafts is the conventional angiography, it poses multiple disadvantages; the most important are invasiveness and patient discomfort. From that point the need to use a less invasive imaging modality has become a must for such purpose (Radwan et al., 2019).

Venous grafts are still the most widely used type of grafts due to their abundance. In our study also, venous grafts were the most common type of grafts. It represented nearly about $61.6 \%$. Yet, there was high rate of complications with venous grafts due to their high rate of occlusion and narrowing. Our study showed that $19 \%$ of the venous grafts were significantly narrowed and about $10.8 \%$ of them were totally occluded. The obtuse marginal (OM) branch was the commonest site for venous graft landing (47\%) followed by the left anterior descending $(27 \%)$.

The insitu arterial grafts are used more common than the free arterial grafts, as the later has higher rate of complications. In our study, $12.5 \%$ of the arterial grafts were free arterial grafts. There was significant narrowing in $14 \%$ of the free arterial grafts, and a $14 \%$ rate of occlusion, raising the rate of complications in free arterial grafts to about $28 \%$ in our study.

Insitu arterial grafts, were one of the most widely used grafts $(84.7 \%)$ of the arterial grafts in our study, especially at the relatively younger patient due to their high patency rates after a long time, yet not abundant. The left internal mammary artery (LIMA) was the most widely used insitu arterial graft $(84.6 \%)$ of the insitu arterial grafts in our study. Due to its arterial nature, it has less incidence rate of complications (Gabriel et al., 2018).

The left anterior descending (LAD) is the most common site for landing of the LIMA graft, as it is the most important coronary artery branch supplying the left ventricle and due to other anatomical considerations as they are both anteriorly located in the chest. $93.7 \%$ of our LIMA grafts ended at the LAD (Bhatnagar et al., 2013).

In a prospective study done by Romagnoli et al., (2010) compared the results with conventional coronary angiography as the standard of reference, According to their findings multi-detector row CT angiography presented a good diagnostic performance, regarding the assessment of occlusion of the grafts. Similar study was done by Monem et al., (2012), with sensitivity $100 \%$ and specificity $96.4 \%$. 


\section{EL-SAYED AHMED SAEED AHMED et al.,}

Compared with conventional angiography, CT angiography was less costly, faster, did not require assembly of an angiographic team to perform the study and is generally more available 24 hours a day. It permitted a wider variety of manipulations of the volumetric data set for image display and analysis in contrast to the limited projections routinely obtained during conventional angiography, and has fewer potential complications (Asai et al., 2015).

\section{CONCLUSION}

MDCT has the ability to evaluate coronary artery bypass grafts.

\section{REFERENCES}

1. Aghayev A, David J. Murphy, Abhishek R. Keraliya, Michael $L$ and Steigner (2016): Recent developments in the use of computed tomography scanners in coronary artery imaging: Expert Review of Medical Devices, 8(5): 545-553.

2. Asai T, Ochi $M$ and Yokoyama $H$ (2015): Off-Pump Coronary Artery Bypass, Pbl Springer; Oct 6. 212- 217.

3. Ascarelli A, FranconeMM, Cannata $D$ and Cannavale A (2010): Role of multidetector CT in the evaluation of coronary artery bypass grafts. Future Medicine- Imaging in Medicine, 2(1):77-86.

4. Bhatnagar G, Vardhanabhuti V, Nensey R, Sidhu $H$ and Roobottom C (2013): The role of multidetector computed tomography coronary angiography in imaging complications post-cardiac surgery. Clinical Radiology J.; 68(5): 254- 265.

5. Gabriel $\mathbf{J}$, Klimach $\mathbf{S}$, Lang $P$ and HildickSmith D (2018): Should computed tomography angiography supersede invasive coronary angiography for the evaluation of graft patency following coronary artery bypass graft surgery?. Interactive CardioVascular and Thoracic Surgery J, 21(2): 231-239.

6. Gaudino $\mathrm{M}$, Antoniades $\mathrm{C}$, Benedetto $\mathrm{U}$ and Deb S (2017): Mechanisms, Consequences, and Prevention of Coronary Graft Failure. Circulation, 136: 1749-1764.

7. Graaf F, Joëlla E. van Velzen and Agnieszka J (2011): Diagnostic performance of 320-slice multi detector computed tomography coronary angiography in patients after coronary artery bypass graftin. European Radiology, 21: 22852296.

8. Levisman JM, Budoff MJ and Karlsberg RP (2011): Long-term coronary artery graft patency as evaluated by 64-slice coronary computed tomographic angiography. Coron Artery Dis., 22(8): 521-5.

9. Monem SA, Nasr A. MS and Algebalay A. MW (2012): Sixty four multi-detector CT coronary angiography: An easy and accurate method to detect graft patency post CABG. EJRNM, 43:377-381.

10. Radwan H, Kandil N, Elshaer $M$ and AbdElkader A (2019): Diagnostic accuracy of 256 slices computed tomography coronary angiography in post coronary artery bypass graft Egyptian patients, Journal of Indian College of Cardiology, 9(3): 154-164 .

11. Romagnoli A, Patrei A and Mancini A (2010): Diagnostic accuracy of 64-slice CT in evaluating coronary artery bypass grafts and of the native coronary arteries. Radiol Med, 115:1167-1178. 


\section{تقييه عمليات وصلات الشرايين التاجية باستخدام الأشعة المقطعية

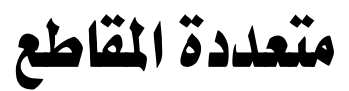

السيد أحمد سعيد أحمد*، أحمد عبد الفتاح أبو راشد*، محمود إبراهيم الشامي*، ** إسماعيل نصر السكري

قسم الأشعة التثخيصية* وقسم جراحة القلب والصدر **، كلية الطب، جامعة الأزهر، القاهرة، مصر

Phone: +201142176200, E-mail: doc.elsayed@ gmail.com

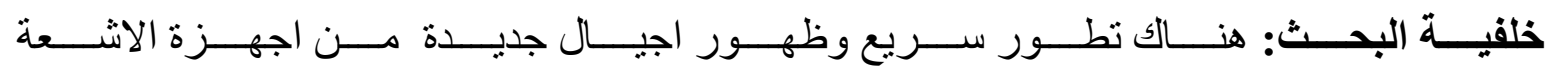

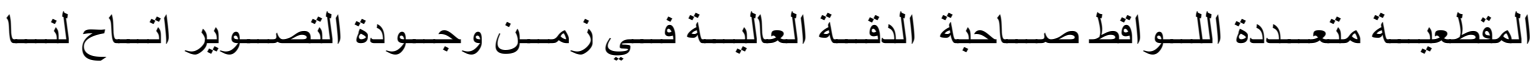

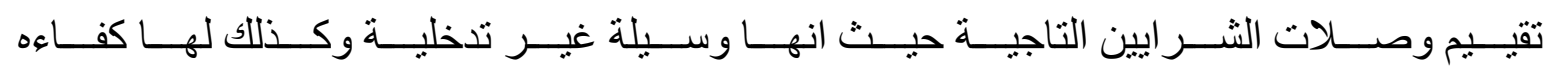

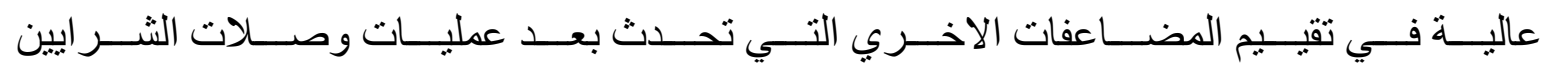

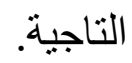

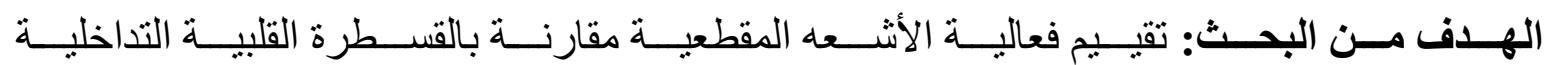
في تقييم عمليات وصلات الثر ايين التاجية.

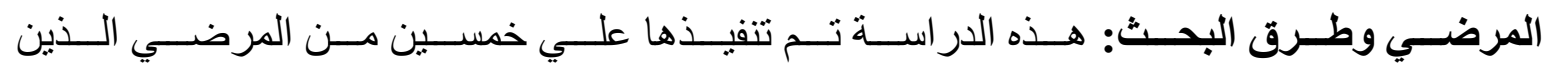

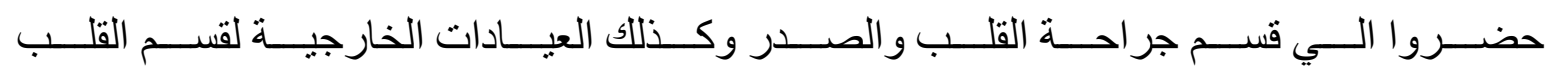

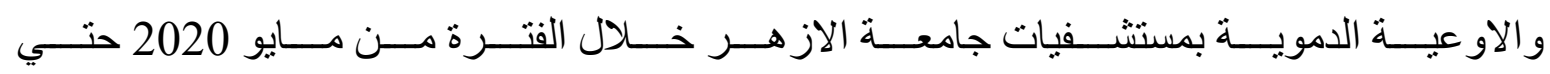

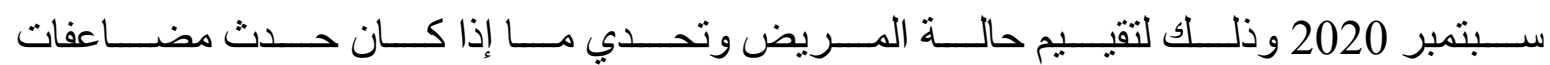

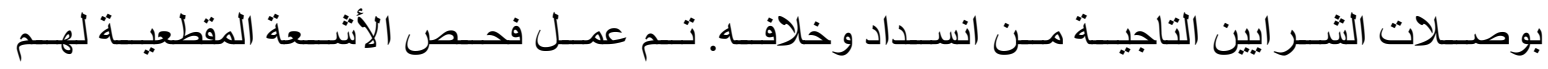

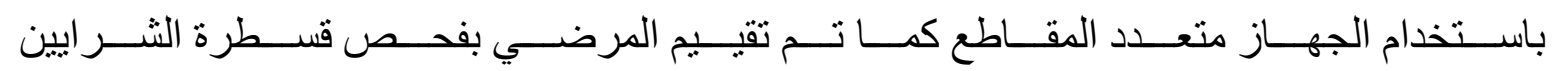

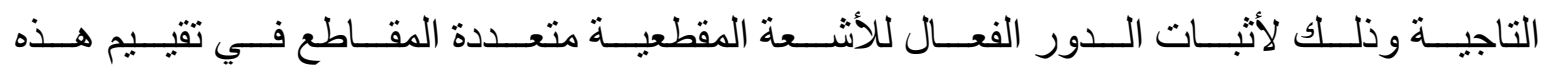

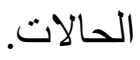

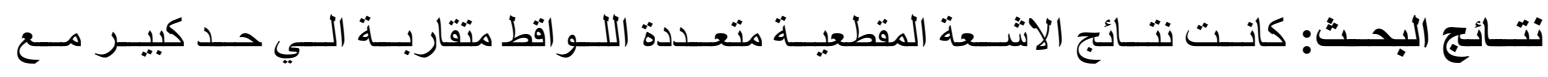

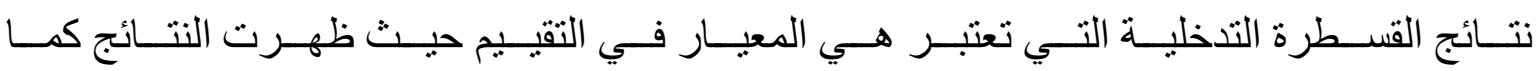




\section{EL-SAYED AHMED SAEED AHMED et al.,}

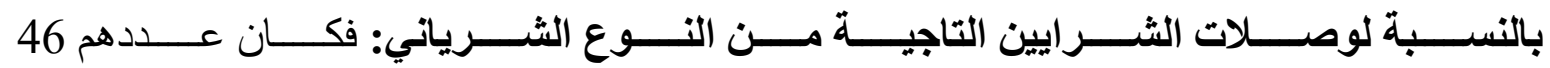

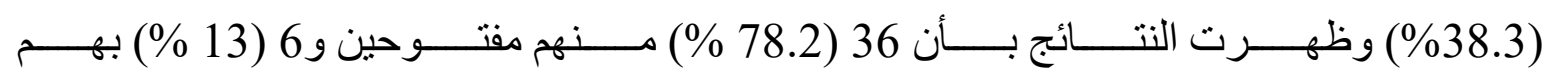
ضيق و4 (8.8 \%) بهم انسداد تام.

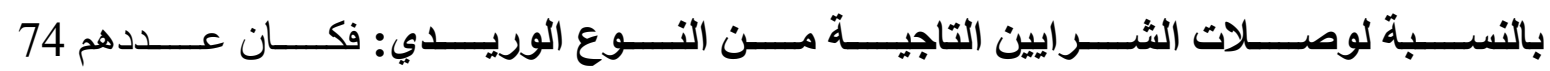

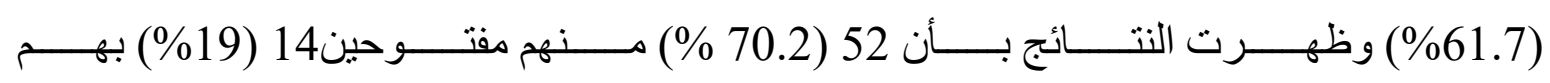
ضيق 8 (8.10\%) بهم انسداد تام.

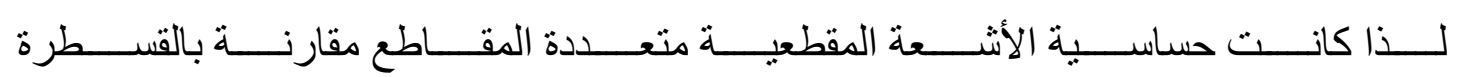
التنخلية هو 100\% ونوعيتها هو 98\% ودقتها هو 93.6\%.

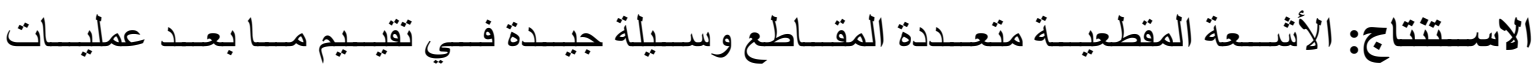
وصلات الثر ايين التاجية حيث أنها وسيلة عامنة وفعالة.

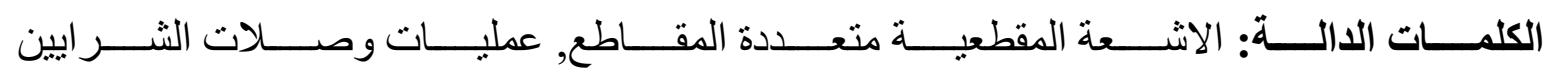
التاجية, امر اض الثريان التاجي. 